\title{
EI PRINCIPIO DE SUBSIDIARIDAD EMPRESARIAL DEL ESTADO
}

\author{
Christian Guzmán Napurí*
}

\section{INTRODUCCIÓN}

En realidad, la doctrina maneja dos conceptos de subsidiaridad en el ámbito del derecho público económico ${ }^{1}$. El primero, que es más amplio, está dirigido a comprender el accionar del Estado como subsidiario de la actuación de los particulares, de tal forma que él mismo interviene cuando estos no pueden obtener por sí mismos el resultado más eficiente, dada la existencia de distorsiones en el mercado como pueden ser los costos de transacción o las externalidades.

El segundo concepto de subsidiaridad estatal, mucho más restringido, está orientado a comprender la actividad empresarial del Estado como aquella que se manifiesta cuando la actividad privada no puede proveer adecuadamente los bienes y servicios necesarios en un mercado determinado, al amparo de lo dispuesto por el artículo 60 de la Constitución. Este último concepto se estudiará de manera amplia en el presente trabajo.

* Director de la Maestría de Derecho Administrativo Económico y del Programa de Especialización en Derecho Constitucional de la Universidad Continental. Socio de GNS Guzmán Napurí \& Segura Abogados. Vocal del Tribunal de la Superintendencia Nacional de Salud y del Tribunal del Servicio Civil. Magíster en Derecho con mención en Derecho Constitucional y Doctorando en Derecho por la Pontificia Universidad Católica del Perú.

1 Es necesario efectuar esta aclaración, puesto que existen diversos conceptos de subsidiaridad provenientes de otros ámbitos del derecho público como, el referido a la subsidiaridad (o residualidad) de los procesos constitucionales o el concepto de subsidiaridad que resulta aplicable a las competencias de los gobiernos locales y regionales en el contexto del proceso de descentralización. 


\section{LA CRISIS DEL ESTADO DE BIENESTAR}

Cuando se hizo patente la aparición del estado de bienestar se generó, como resultado inmediato, la necesidad de una administración pública que fuera prestadora de servicios ${ }^{2}$. Dichos servicios debían ser prestados por el Estado en forma directa, a través de mecanismos de gestión. Paulatinamente, conforme las necesidades de la población aumentaban, fue necesario que el Estado creara entes especializados para la prestación de dichos servicios.

Seguidamente, debido a que los mecanismos tradicionales de la administración pública resultaban poco efectivos para la prestación de los referidos servicios, fue preciso tomar prestados algunos conceptos de la administración privada para hacer eficiente la gestión de los mismos. Como resultado, surgieron las llamadas empresas públicas, en general definidas como personas jurídicas de derecho privado, pero que eran y son de propiedad del Estado y que interactúan en el mercado, algunas veces excluyendo a los particulares.

Asimismo, las décadas del cincuenta y sesenta del siglo pasado se habían caracterizado por la bonanza económica en los países más adelantados y cierta mejoría en los demás países del orbe, que les permitía el manejo directo de determinadas actividades, muchas de ellas reservadas al Estado ${ }^{3}$. Sin embargo, la crisis energética de 1970, entre otras circunstancias, afectó el manejo económico de las naciones, por ello se comenzó a pensar seriamente en la necesidad de transferir a manos privadas el manejo de determinadas actividades, sean estas servicios públicos o no.

2 Sobre el particular, véase DE VAL PARDO, I. Administración de entidades públicas. Madrid: Instituto de Estudios Económicos, 1999, pp. 49-51.

3 KRESALJA, B. (1999). El rol del Estado y la gestión de los servicios públicos. Themis n. ${ }^{\circ}$ 39. Lima: Pontificia Universidad Católica del Perú, 1999, pp. 55.
Lo que ocurre es que hablar de empresa pública implica, de alguna manera, una contradictio in terminis, dado que en principio las empresas son entes creados para la producción de lucro, entendido este como la ganancia de sus dueños. Asimismo, el Estado, por definición, no produce lucro ${ }^{4}$. Tal contradicción, aunada al hecho de que los representantes del Estado en las juntas de las empresas estatales carecen de incentivos económicos (dividendos), incentivos que los socios de una empresa privada ${ }^{5}$ sí poseen, ha generado la conocida ineficiencia de las empresas públicas en la mayoría de las naciones del planeta ${ }^{6}$, como veremos más adelante.

Finalmente, encontramos la razón de la citada ineficiencia pública en la necesaria rigidez y formalidad del funcionamiento del Estado en general. Dicha rigidez impide que las empresas del Estado se adapten rápidamente a la vertiginosa variación de los mecanismos empresariales derivada del progreso económico y tecnológico en todo el mundo, lo cual ocurre con mayor facilidad en el caso de las empresas que son de capital privado.

Así, la empresa pública genera distorsiones en la economía, al crear entes económicos que no están sometidos al mercado de manera integral. Además, utiliza fondos públicos para su funcionamiento; sin embargo, no son susceptibles de incurrir en insolvencia y emplean infraestructura del Estado. Como resultado de

4 GUZMAN, C. (2002). «Las teorías existentes sobre el servicio público». Foro Jurídico n. ${ }^{\circ} 1$. Lima: Pontificia Universidad Católica del Perú, 2002, p. 77.

5 Es evidente que la razón por la cual las empresas privadas pretenden obtener ganancias como finalidad intrínseca de las mismas (de lo contrario no serían empresas) es la propia necesidad o afán de lucro de sus dueños.

$6 \mathrm{Al}$ respecto, véase ARIÑO, G., De La Cuétara, J. y Martínez, J. L. El nuevo servicio público. Madrid: Marcial Pons, 1997, p. 112 y ss. 
ello, cuando las empresas públicas operan en el mercado, concurriendo con entes privados, generan competencia desleal, que perjudica a la economía en su conjunto.

\subsection{Privatización de las empresas públicas}

Como resultado inmediato de la ineficiencia de las empresas públicas - y del Estado en general-, se generaron dos efectos: el primero, está relacionado con la privatización de aquellas empresas públicas que no producen utilidades o que generan distorsiones en la economía, privatización que también generaría el ingreso de importantes fondos para el Estado para corregir el déficit en el sector público y controlar los presupuestos ${ }^{7}$. Este proceso estuvo acompañado de la eliminación de la reserva de determinadas actividades a favor del Estado.

En términos generales, la privatización es el fenómeno mediante el cual una actividad desempeñada por el Estado es adjudicada a los particulares, quienes obtienen el permiso, a través de un título habilitante determinado, para realizar dicha actividad, ya sea que el Estado mantenga un control más o menos intenso sobre ella o más bien la ceda de manera integral a la sociedad ${ }^{8}$. La privatización puede entenderse también como la transferencia de activos o bienes estatales a manos privadas, tal como precisamente ha ocurrido con muchas de las empresas estatales del Perú.

7 DE VAL PARDO, I. Op. cit., pp. 90 y ss. Al contrario de lo que señala la autora, debemos señalar que no es posible que la administración pública, en términos de servicios públicos, pueda funcionar adecuadamente sin privatizarlos. Tal como lo hemos precisado, la ineficiencia de las empresas públicas resulta ser, en principio, consustancial a ellas.

8 ARIÑO, G. Principios de derecho público económico. Granada: Comares, 1999 , pp. 440-441.
Por otro lado, se generó un segundo efecto que fue la necesidad de suscitar una importante inversión en servicios públicos, que a su vez obligó al Estado a permitir el ingreso de capital privado a la administración de fondos y bienes públicos y la prestación de servicios públicos, a través, particularmente, de mecanismos de privatización y de otorgamiento de concesiones, entre otras, asociaciones públicas privadas, conforme a la normativa vigente sobre la materia.

Lo antes indicado se estableció mediante diversos mecanismos, en especial los relacionados con los permisos, las licencias y las concesiones, otorgadas de manera directa por el Estado. Y, además, ocasionó la aparición de los llamados organismos reguladores, como Osinergmin (Organismo Supervisor de la Inversión en Energía y Minería), Osiptel (Organismo Supervisor de Inversión Privada en Telecomunicaciones), Ositran (Organismo Supervisor de la Inversión en Infraestructura de Transporte de Uso Público), SUNASS (Superintendencia Nacional de Servicios de Saneamiento), así como diversos organismos supervisores y fiscalizadores de diversas actividades productivas, como pueden ser los diversos ministerios.

En consecuencia, fue necesario que los servicios públicos comenzaran a ser prestados por los particulares. A esto la denominada teoría subjetiva respondió de manera indebida, pues consideró que en realidad la prestación la realizaba el Estado, pero de manera indirecta a través de terceros?. Según esta concepción, el servicio brindado por los particulares ocurre como una suerte de delegación. Esta ficción, sin embargo, nos lleva a la necesidad de establecer otro nivel de caracterización que resulte más eficiente, es decir los servicios públicos de-

9 DROMI, R. Derecho administrativo. Buenos Aires: Ciudad Argentina, 2000, p. 627. 
bían ser prestados, fundamentalmente, por los particulares, razón por la cual la participación del Estado debía darse a falta de posibilidad de intervención de la actividad privada.

\section{EL PRINCIPIO DE SUBSIDIARIDAD EMPRESARIAL}

Como ya se ha señalado, se entiende por principio de subsidiaridad, en sentido estricto, la obligación que posee el Estado de realizar actividad empresarial únicamente ante la ausencia de inversión privada en el rubro respectivo, y previo cumplimiento de los parámetros establecidos por la norma constitucional. Ahora bien, a fin de hacer efectivo dicho principio, se debe cumplir con tres requisitos:

\section{i. Autorización por ley expresa, es decir, emitida por el Congreso}

Ello implica, en primer lugar, que la autorización para desempeñar actividad empresarial debe estar ligada de manera directa a la necesaria discusión entre las diversas fuerzas políticas representadas en el Parlamento. En general, cuando la Constitución hace referencia a la ley se refiere a la norma emitida por el Congreso, la cual debe distinguirse claramente de otras normas de inferior jerarquía, siendo que no cabe autorizar actividad empresarial a través de reglamentos o directivas.

En segundo lugar, no cabe autorización alguna a través de decretos legislativos, decretos de urgencia u ordenanzas, sean regionales o municipales. Si bien dichas normas poseen lo que se denomina rango de ley - con las atingencias que la jurisprudencia ha efectuado en relación a las ordenanzas-, no han sido emitidas como resultado de la deliberación parlamentaria.
En tercer lugar, debe entenderse que estamos hablando de una ley cuya aprobación sigue el trámite normal, a diferencia del caso chileno, por ejemplo, donde se requiere quórum calificado ${ }^{10}$ (Ochoa, 1995, pp. 88-89). Sin embargo, esto se encuentra todavía en manos del Estado, sin visos de ser privatizada; a pesar de no existir razón alguna, desde el punto de vista económico, para mantenerla en su titularidad; teniendo en cuenta que fue adquirida por expropiación. Para hacerlo, es necesario considerar que se requiere una reforma constitucional, puesto que se considera que la Constitución chilena prohíbe la privatización de la gran minería del cobre ${ }^{11}$.

\section{ii. Por razón de alto interés público o de manifiesta conveniencia nacional}

Vale decir, la actividad empresarial del Estado se encuentra autorizada en estado de necesidad, cuando no exista algún mecanismo alternativo que pueda corregir la situación que genera la necesidad de desempeñar dicha actividad por parte del Estado, como el empleo de las agencias de competencia o los mecanismos de regulación económica.

El empleo de la actividad empresarial del Estado en tanto constituye una interven-

10 OCHOA, C. (1995). Bases fundamentales de la Constitución económica de 1993. La Constitución de 1993, análisis y comentarios. Lima: CAJ, 1995, pp. 88-89.

11 Existen casos interesantes de mantenimiento de empresas estatales por mandato constitucional. Probablemente el ejemplo más conocido sea el de PEMEX, empresa mexicana de hidrocarburos, cuya privatización se encuentra prohibida por la constitución mexicana; siendo esta una de las principales razones de su proverbial ineficiencia. Si bien es una empresa que produce lógica utilidad, está absorbida por el propio Estado a través de fuertes impuestos, llevándola a una situación financiera compleja. El riesgo, si es que ello no ha pasado ya, es que PEMEX ya haya perdido el íntegro de su capital contable. 
ción pública directa en la economía, debe ser, en consecuencia, última ratio. A ello debe agregarse que dicha intervención debe ser idónea, lo que implica que debe dirigirse a obtener la finalidad pretendida con ella. Caso contrario, dicha intervención devendría en inconstitucional por vulnerar lo dispuesto por la norma.

\section{iii. Ante la ausencia de actividad privada en el sector del cual se trata}

El Estado interviene y desempeña actividad empresarial si es que los particulares no pueden hacerlo, puesto que si existe actividad privada la actividad estatal deviene innecesaria ${ }^{12}$. El criterio empleado por el Estado es la prohibición de intervención en aquellos mercados en los que la oferta de las empresas privadas se considera suficiente para satisfacer la demanda existente en todo el territorio nacional o en la parte en donde atienden; siendo que se presume, salvo demostración en contrario, que tal condición se verifica en aquellos mercados en los que operan al menos dos empresas privadas no vinculadas entre $s^{\prime 13}$.

Asimismo, cuando no es posible que la actividad privada cubra la deficiencia en la inversión, es necesario establecer mecanismos que lo hagan. Sin embargo, incluso en estos supuestos también existen mecanismos que

12 KRESALJA. Op. cit., p. 60.

13 No obstante ello, el ordenamiento jurídico peruano posee una válvula de salida cuya existencia es muy discutible. El párrafo final del artículo $3^{\circ}$ del Decreto Supremo 0342001-PCM establece la prohibición que hemos señalado, pero también permite que no sea aplicable a las actividades que el Directorio de Fonafe determine específica e individualmente. Así en estos casos, el citado Directorio tomará en cuenta el aprovechamiento de la capacidad operativa de las empresas, pudiendo establecer limitaciones al incremento o la renovación de dicha capacidad. permiten cubrir deficiencias y no implican la creación o empleo de empresas públicas, como, por ejemplo, la asignación de cuotas de inversión a las empresas privadas que prestan servicios públicos.

El principio de subsidiaridad tiene sentido en el hecho de que la actividad empresarial del Estado debe encontrarse fuertemente limitada, no solo por el hecho de que el Estado es un empresario ineficiente, sino además porque la existencia de empresas públicas es per se indebida desde el punto de vista económico. Las empresas públicas no solo generan competencia desleal respecto de las empresas privadas que concurren en el mercado, sino que también favorecen la corrupción y desincentivan la inversión en el mercado de servicios públicos y en la economía en general, como veremos enseguida. Como resultado, la economía de un país debe propender a la privatización de las empresas públicas y a la sustitución del régimen de control estatal a un esquema de competencia ${ }^{14}$.

\section{El acercamiento jurisprudencial}

El Tribunal Constitucional se ha pronunciado sobre el particular, estableciendo una definición de subsidiaridad vinculada al supuesto carácter social del modelo económico consagrado por la Constitución, en tanto que el Estado no debe permanecer pasivo ante el ejercicio de las actividades económicas por los particulares ${ }^{15}$.

14 Para un análisis de las ventajas de la privatización a partir de las deficiencias de las empresas públicas, véase VICKERS, J. y YARROW, G. Un análisis económico de la privatización. México: Fondo de Cultura Económica, 1991, pp. 44 y ss.

15 STC N. $^{\circ}$ 01535-2006-AA/TC, 31 de enero de 2008. 
En este orden de ideas, el Tribunal ha señalado que el principio de subsidiariedad económica del Estado o, lo que es lo mismo, la cláusula de actuación subsidiaria del Estado en la economía implica, de un lado, un límite a la actividad estatal, siendo que el Estado no puede participar libremente en la actividad económica, sino que sólo lo puede hacer sujeto a la subsidiariedad, entendida esta como una función supervisora y correctiva o reguladora del mercado; y, de otro lado, reconocer que existen ámbitos que no pueden regularse única y exclusivamente a partir del mercado, lo cual justifica la función de regulación y protección que desempeña el Estado ${ }^{16}$.

Ahora bien, es evidente que el Tribunal Constitucional confunde los dos conceptos de subsidiaridad propios del derecho público económico a los cuales hemos referido al inicio de este trabajo; cuando resulta evidente que el artículo $60^{\circ}$ de la Constitución hace referencia a la subsidiaridad empresarial. La subsidiaridad económica, en sentido amplio, se encuentra en el artículo $58^{\circ}$, que consigna el concepto de iniciativa privada libre.

Asimismo, el Tribunal continúa señalando que el fundamento ${ }^{17}$ del principio de subsidiaridad parte del supuesto de que el Estado aparece como el garante final del interés general, desde el momento en que su tarea consiste en intervenir en forma directa para satisfacer una necesidad real de la sociedad, pero sólo en aquellas situaciones en las que la colectividad y los grupos sociales - a quienes corresponde, en primer término, la labor de intervenciónno están en condiciones de hacerlo.
El Tribunal además confunde el origen del principio que venimos describiendo. La norma no pretende definir la existencia de atribuciones públicas por parte del Estado en materia de intervención económica, sino más bien limitar su atribución de crear empresas estatales, asimismointenta evitar que el Estado intervenga en la actividad económica de manera directa como un actor, ya que su función primordial es actuar como árbitro de las relaciones económicas y cuando ello sea estrictamente indispensable.

\section{¿Existe algún mecanismo de control?}

La respuesta es afirmativa. Desde la emisión del Decreto Legislativo 1044, Ley de Represión de la Competencia Desleal, se define como acto de competencia desleal, en la modalidad de violación de normas, la actividad empresarial desarrollada por una entidad pública o empresa estatal con infracción al artículo $60^{\circ}$ de la Constitución, descrito líneas arriba ${ }^{18}$. Esta es una novedad de dicha norma, puesto que la norma derogada no consignaba precepto alguno sobre el particular.

Como resultado, este precepto permite al Indecopi o a Osiptel, en su caso, controlar la actividad empresarial del Estado, impidiendo así que se vulnere la libre y leal competencia. En primer lugar, resultaba indispensable la existencia de un real mecanismo de control, más allá de los informes que dichas entidades emitían, que carecían de un efecto jurídico real. A esta situación nos vamos a referir con detalle más adelante.

En segundo lugar, dicho control no podría ser asignado al Fondo Nacional de Financia-

18 Artículo $14^{\circ}$ del Decreto Legislativo 1044.

16 Fundamento 14.

17 Fundamento 16. 
miento de la Actividad Empresarial del Estado (Fonafe) —ya que pasaría a ser juez y parte en este contexto- ni tampoco al sector al que pertenece la empresa estatal en cuestión. Un punto a dilucidar se encuentra relacionado con la competencia de la autoridad competente para cuestionar la ley que faculta el ejercicio de la actividad empresarial. Está claro que no debiera existir impedimento alguno para ello, dadas las atribuciones otorgadas por el Tribunal Constitucional a favor de la administración pública para aplicar el control difuso de constitucionalidad de las leyes.

Finalmente, es evidente que en este caso no se requiere acreditar la adquisición de una ventaja significativa por quien desarrolla dicha actividad empresarial, requisito exigido para encontrarnos ante un acto de competencia desleal en la modalidad de violación de normas, puesto que se asume que toda actividad empresarial del Estado que viole el principio de subsidiaridad genera por sí misma una ventaja indebida a favor de dicha empresa en el mercado.

\section{3. ¿POR QUÉ DEBE LIMITARSE LA EXISTENCIA DE EMPRESAS PÚBLICAS?}

La existencia de empresas públicas per se afecta de manera perjudicial a la economía de un país, cualquiera sea el diseño de su política económica. En este orden de ideas, aun en el supuesto de que las empresas públicas produzcan utilidades, su implementación debe limitarse a los presupuestos señalados en el acápite precedente, vale decir, cuando sea estrictamente indispensable. Entre las razones más importantes que justifican dichas afirmaciones, encontramos las siguientes ${ }^{19}$ :

19 Para un interesante análisis de este punto, revisar Paredes, C. (2020). La tragedia de las empresas sin dueño: el caso Petroperú. Huancayo: Fondo Editorial de la Universidad

\section{i) El árbitro no debería jugar}

Una razón de índole jurídica, en primer lugar, es que cuando el Estado posee empresas públicas y se comporta a la vez como regulador del mercado —en ejercicio de sus potestades reguladoras - y como agente del mismo, lo cual lo convierte en un competidor, en un regulador de la competencia, así como en el ente que resuelve los posibles conflictos, lo cual le impide ser realmente imparcial. A ello se debe agregar que todo tratamiento diferenciado es eminentemente inconstitucional, pues vulnera el precepto final del artículo constitucional materia de comentario, el cual prescribe con meridiana claridad el tratamiento igualitario entre inversión privada y pública.

Asimismo, las empresas públicas generan competencia desleal, puesto que gozan de privilegios de los cuales no gozan las empresas privadas, como por ejemplo, empleo de la infraestructura estatal (que forma parte de sus activos originarios), uso de la caja (dinero estatal). Incluso, como lo hemos señalado líneas arriba, la propia normativa en materia de competencia desleal considera que constituye un comportamiento ilegal el ejercicio de actividad empresarial pública que viole el principio de subsidiaridad.

Asimismo, estas empresas no quiebran, porque el Estado les provee caja (dinero) ${ }^{20}$, y en general, gozan de blandas restricciones presupuestarias $^{21}$. Y todo ello se hace efec-

Continental.

20 ARIÑO. Op. cit., pp. 391-392.

21 Para una posición contraria, cfr. Cespedes, A. "Conjeturas sobre algunos aspectos generales el funcionamiento y la regulación de las empresas públicas peruanas”. En: Revista de Derecho Administrativo n. ${ }^{\circ}$ 5, Lima: Pontificia Universidad Católica del Perú, 2008, pp. 278-279. 
tivo con el dinero proveniente de los contribuyentes, lo cual lejos de generar efectos beneficiosos, ocasiona más bien efectos de contracción en la economía.

En contraposición, la completa apertura del mercado incentiva a los empresarios a invertir, generando así mayor competencia, siendo los efectos más favorables. En consecuencia, la principal razón para la privatizacion de empresas estatales no se dirige a producir beneficios económicos — que debe ser más bien una necesidad subalterna- o a reducir el déficit fiscal, sino más bien a crear competencia en el mercado, con el consiguiente beneficio en términos del interés general.

Finalmente, en términos de la teoría de juegos $^{22}$, lo ideal es que el árbitro decida por el completo imparcial, es decir, que no demuestre interés en el resultado del juego. Si es que el Estado es propietario de empresas y a su vez se encarga de regular el mercado, existiría un riesgo ya que es posible que genere dicha regulación en favor de sus empresas, a lo que debemos agregar que el Estado es además el encargado de resolver los conflictos que se generen entre las empresas. Como efecto, la existencia de empresas públicas debe ser estrictamente indispensable, debiendo generarse mecanismos de control que eviten esta situación en lo posible.

\section{ii) El afán de lucro}

La empresa pública, como lo hemos señalado, constituye una contradictio in terminis,

22 Respecto a la utilidad de la teoría de juegos en el derecho público y en particular en el derecho constitucional, véase GUZMAN, C. La constitución política: Un análisis funcional. Lima: Gaceta Jurídica, 2015, pp-12-13. puesto que por definición una empresa produce lucro. Pero, una institución pública, supuestamente animada por el interés general, no tiene porqué producir dicho lucro. Una justificación para la existencia de empresas públicas estriba en la necesidad de producir a nivel del costo marginal, lo cual, tarde o temprano, las hace sucumbir ante la competencia.

Otra de las justificaciones esgrimidas para la creación de empresas públicas se basa en la necesidad de que el Estado produzca beneficios económicos al igual que los agentes privados, lo cual resulta evidentemente contradictorio, máxime si una empresa pública existe, supuestamente, por razones sociales $\mathrm{y}$ no por razones financieras.

Como resultado, no existen incentivos adecuados para los agentes de las empresas públicas, tampocoexiste interés alguno para la generación de excedentes ya que así sean infecientes no estan sujetas a las sanciones del mercado ${ }^{23}$. Como no hay objetivos definidos, no puede determinarse juicios sobre la buena o mala gestión, el grado de eficiencia obtenido y la valoración de resultados finales ${ }^{24}$.

Los incentivos económicos se convierten en una forma de patronazgo y - como lo veremos más adelante- en el mecanismo de pago de favores políticos para el partido en el poder. Como si esto fuera poco, los políticos que supervisan empresas públicas podrían dejar de percibir beneficios personales

23 KRESALJA, B. "La reserva de actividades económicas a favor del Estado y el régimen de los monopolios en las Constituciones de 1979 y 1993”. Ius et Veritas año 11, n. ${ }^{\circ}$ 22. Lima: Pontificia Universidad Católica del Perú, 2001, pp. 286.

24 VICKERS y YARROW. Op. cit., p. 49 
como resultado de la obtención de beneficios económicos por parte de la empresa ${ }^{25}$. En ese sentido, se requiere que los directores de las empresas públicas sean designados por concurso público.

\section{iii) Distorsiones en la economía}

En consecuencia, la existencia de empresas estatales genera distorsiones en la economía. Para que el funcionamiento de estas sea acorde con las necesidades sociales — que es en buena cuenta su razón de ser-, el precio del producto o servicio ofertado debe ser el menor posible; para ello, el monto debe estar a nivel del costo marginal ${ }^{26}$ (Bernanke y Frank, 2007, pp. 12-13) , y cuando ello ocurre, la pérdida económica y contable de la empresa la convierte en un ente ineficiente, condenándola a la quiebra, como ya se hemos señalado. La banca de fomento, muy difundida durante la década de 1980, es un muy buen ejemplo de ello.

Por otro lado, los bienes públicos, en general, ocasionan distorsiones per se, dado que no permiten un uso eficiente de los recursos. Lo que ocurre en buena cuenta es que la propiedad pública no genera incentivos para un uso eficiente. Siendo así, el mercado no podrá ofrecer los bienes públicos en número suficiente, lo que a su vez implica que no se asignarán suficientes recursos para producirlos ${ }^{27}$. Los bienes públicos originan la existencia de los denominados free riders, denominación que se le da a

25 ARIÑO, G. Op. cit., p. 422.

26 El costo marginal de una actividad se define como el costo de una unidad adicional de dicha actividad. Sobre el particular, cfr. Bernanke, B. y Frank, R. Principios de economia. Madrid: McGraw-Hill, 2007, pp. 12-13.

27 KAFKA, F. Teoría económica. Lima: Universidad del Pacífico, 1994, p. 741. aquellos individuos que se benefician sin pagar, de modo que se afecta a los que sí lo hacen. Dicha situación no hace sino generar externalidades, las cuales producen imperfecciones en el mercado.

\section{iv)Falta de incentivo a la inversión}

La empresa pública desincentiva la inversión. El hecho de que existan empresas privilegiadas en el mercado - por ser propiedad estatal — evita que las empresas privadas puedan invertir, dada su evidente aversión al riesgo, la cual empeora en situaciones de crisis. A la vez, la existencia de empresas públicas —en especial si algunas gozan del manejo de alguna actividad en exclusividad, como el agua- da la impresión de que la economía se encuentra fuertemente intervenida, lo cual aleja la inversión privada, sea local o foránea. Antes de constituir una empresa pública, es preferible incentivar la inversión privada en el rubro donde existe la deficiencia de la oferta a fin de generar los bienes y servicios necesarios.

\section{v) Favorecimiento de la corrupción}

Es poco probable que una empresa privada sufra de corrupción en su interior en contra de sí misma, ya que los socios son también sus directivos. Sin embargo, en una empresa pública, se favorece la corrupción, dado que por pertenecer al Estado, no existen incentivos para un comportamiento ajustado a derecho.

La empresa privada no requiere mayores controles internos que los que proporciona su propia organización. En cambio, las empresas públicas requieren controles internos y controles externos de naturaleza 
administrativa, en especial provenientes de la Contraloría General de la República y de Fonafe, en los casos en los cuales se someten al ámbito de esta última. Dicho control, contrariamente a lo que pueda pensarse, también cuesta a los particulares a través del sistema impositivo.

\section{vi)Distribución de cargos públicos}

La empresa estatal favorece el uso del denominado spoils system (sistema de los despojos), que consiste en el hecho de que el partido ganador en las elecciones ocupe gran parte de los cargos públicos del Estado ${ }^{28}$. Los cargos más codiciados son los que corresponden a las empresas del Estado, que se encuentran por lo muy bien remunerados. Como resultado, los directivos de las empresas públicas no son los que están mejor capacitados para efectuar la labor, por ello deberían ser designados mediante sendos concursos públicos. Más adelante se ampliará al respecto. Esta situación explica las pérdidas millonarias que han sufrido las empresas estatales en todo el mundo en los últimos treinta años. Los ejemplos de empresas estatales relativamente exitosas son más bien bastante raros, se reducen a aquellas que realizan actividades extractivas (Codelco, en Chile, por ejemplo), asimismo y tienen utilidades menores, en comparación con aquellas que si fueren administradas por inversionistas privados. Además, algunas son empleadas como caja chica del Estado.

28 El spoils system no es ninguna novedad; ha sido aplicado en gran medida por los gobiernos en todo el mundo, especialmente, en los Estados Unidos, incluso desde el gobierno del presidente Jackson. Sobre el particular, cfr. Hauriou, 1980, p. 539 y Duverger, 1962, p. 348.

Sobre el particular: HAURIOU, A. Derecho constitucional e instituciones politicas. Barcelona: Ariel, 1980, p. 539 y DUVERGER, M. Instituciones Politicas y Derecho Constitucional. Barcelona: Ariel, 1962, p. 348.

\section{REGULACIÓN ACTUAL DE LA ACTIVIDAD EMPRESARIAL DEL ESTADO ${ }^{29}$}

En el Decreto Legislativo 1031, establece la regulación actual de la actividad empresarial del Estado, mediante el cual se promueve la eficiencia de la actividad empresarial del Estado, emitido en aplicación de la Ley 29157, la cual delegó en el Poder Ejecutivo la facultad de legislar sobre diversas materias relacionadas con la implementación del acuerdo de promoción comercial Perú - Estados Unidos de América. Curiosamente, en su momento la referida norma fue objeto de críticas por parte de sectores diversos, sea porque se ha considerado que no se encuentra en consonancia con el principio de subsidiaridad, sea porque se ha considerado que debilita la actividad empresarial del Estado y abre las puertas a la privatización de empresas públicas.

En el primer caso, se señala que se ha desperdiciado la oportunidad de establecer mecanismos para que las empresas del Estado sean realmente subsidiarias, definiendo debidamente cuándo nos encontramos ante dicha situación y los mecanismos a emplear cuando ello no ocurra. No obstante, la finalidad de la norma es adecuarla al principio de subsisiaridad y el de igualdad en el tratamiento legal de las empresas $^{30}$. Asimismo, se discute mucho el mecanismo de designación de los directores de las empresas, ya que este no debería ser efectuado por el Poder Ejecutivo, sino más bien a través de un proceso de selección, como veremos más adelante.

En el segundo caso, se argumenta que la norma permite privatizar las empresas públicas a tra-

29 Cfr. GUZMAN, C. Procedimiento Administrativo General. Lima: Instituto Pacífico, 2020, p. 208 y ss.

30 Decreto Legislativo N. ${ }^{\circ} 1031$, pp. 3 y ss. 
vés de la participación de estas en la actividad privada, pudiendo incluso cotizar en la Bolsa de Valores. Diversos sindicatos, por ejemplo, acusaron en su momento al Gobierno de pretender facilitar los mecanismos de transferencia al sector privado del control de las empresas estatales $^{31}$, sobre todo si estas son estratégicas; concepto por completo discutible, en especial si consideramos que los diversos autores no tienen claro qué debe entenderse por dicho término.

\section{1 Ámbito}

La norma materia de comentario establece que la actividad empresarial del Estado se desarrolla en forma subsidiaria, es autorizada por Ley del Congreso de la República y sustentada en razón del alto interés público o manifiesta conveniencia nacional, en cualquier sector económico, sin que ello implique una reserva exclusiva a favor del Estado o se impida el acceso de la inversión privada, lo cual —como bien sabemos - se encuentra prohibido.

Esto define legalmente el principio de subsidiaridad establecido en la Constitución, sin establecer debidamente cuando nos encontramos ante la violación de dicho principio y el mecanismo que habría de emplearse para revertirlo. Es preciso tener en cuenta que este decreto legislativo es anterior a la Ley de Represión de la Competencia Desleal, que sí establece el mecanismo de control respectivo, como veremos más adelante.

Asimismo, se señala que las empresas estatales se rigen por las normas de la actividad empresarial del Estado y de los sistemas administrativos del Estado, en cuanto sean aplicables, y supletoriamente por las normas que rigen la actividad empresarial privada, principalmente

31 La República, 10 de julio y 17 de agosto de 2008 por la Ley General de Sociedades y el Código Civil. Ello implica que el régimen de dichos entes es mixto, entre la regulación proveniente del derecho administrativo y la que corresponde al derecho privado.

\subsection{Formas en que se desarrolla la actividad empresarial del Estado}

La norma en su artículo $4^{\circ}$ prescribe que la actividad empresarial del Estado se desarrolla bajo determinadas formas. En primer lugar, las empresas del Estado de accionariado único, que son empresas organizadas bajo la forma de sociedades anónimas en las que el Estado ostenta la propiedad total de las acciones y, por tanto, ejerce el control íntegro de su Junta General de Accionistas. Esta modalidad en realidad implica una desnaturalización del concepto de Sociedad Anónima, la cual por definición se compone de una pluralidad de socios.

En segundo lugar, están las empresas del Estado que poseen accionariado privado, y son aquellas empresas organizadas bajo la forma de sociedades anónimas, en las que el Estado ostenta la propiedad mayoritaria de las acciones y, por tanto, ejerce el control mayoritario de su Junta General de Accionistas, existiendo accionistas minoritarios no vinculados al Estado. Esto es lo que se llamaba antiguamente empresa de economía mixta y es a lo que debería accederse como resultado de las reformas implementadas por la norma que venimos analizando.

Asimismo, debemos incluir en este listado a las empresas del Estado con potestades públicas, que son empresas de propiedad estatal, cuya ley de creación les otorga potestades de derecho público para el ejercicio de sus funciones. Como resultado, se organizan bajo la forma 
que dispone su ley de creación. Un ejemplo interesante es el del Banco de la Nación. Esta modalidad es más bien rara, lo más común son las dos formas anteriores.

Finalmente, y a diferencia de lo que ocurría con la norma previa, el accionariado estatal minoritario en empresas privadas no constituye actividad empresarial del Estado y se sujeta a las disposiciones de la Ley General de Sociedades y demás normas aplicables a tales empresas. Esto es por completo razonable, puesto que no existe razón alguna para tratar al Estado, que es accionista minoritario de una empresa privada, de manera distinta al tratamiento de cualquier otro accionista.

\subsection{La designación del directorio de las em- presas públicas}

La norma materia de comentario preceptúa, en primer lugar, que para ser director de una empresa del Estado se requiere ser una persona capaz, reconocida por su trayectoria profesional, poseer solvencia ética y moral, estar familiarizada con el giro propio del negocio que realiza la empresa, y poseer una amplia experiencia en la toma de decisiones estratégicas y de gestión empresaria $^{32}$. La finalidad de la norma es mejorar la regulación de los directorios de las empresas públicas, que se había identificado que no era buena en la normativa previa ${ }^{33}$.

Se establece, asimismo, en la norma ${ }^{34}$ que la evaluación de las personas propuestas para integrar los directorios de las empresas del Estado se realizará conforme al procedimiento que disponga el Reglamento ${ }^{35}$. En este orden de ideas, la citada norma muestra dos modalida-

32 Decreto Legislativo N. ${ }^{\circ}$ 1031, artículo 7, numeral 7.1.

33 Decreto Legislativo N. ${ }^{\circ} 1031$, pp. 9-10.

34 Decreto Legislativo N.o 1031, artículo 7, numeral 7.2.

35 Aprobado mediante Decreto Supremo N. ${ }^{\circ}$ 176-2010-EF. des de selección ${ }^{36}$, en la primera los directores son seleccionados por Servir o por entidades o empresas especializadas, lo que puede generar un nivel de autonomía y eficiencia óptimos.

La norma dispone que las empresas del Estado bajo el ámbito de la Fonafe, con excepción de ella, deberán contar con por lo menos un director seleccionado bajo este mecanismo, quien no deberá tener vinculación con la administración de la empresa, sus accionistas, directores ni miembros de la plana gerencial, siendo que dicha persona deberá reunir las condiciones que aseguren su imparcialidad, objetividad e independencia.

El Reglamento instituye una segunda modalidad de designación, en la cual los directores son seleccionados siguiendo el Procedimiento para la Evaluación de las Personas Propuestas como Miembros de los Directorios de las Empresas en las que Fonafe participa como accionista, que es aprobado mediante el Decreto Supremo N.o 085-2006-EF o norma que lo sustituya.

Asimismo, dicho decreto supremo establece el procedimiento de selección, estableciendo puntajes para efectuar la evaluación respecti$\mathrm{va}^{37}$. El problema del procedimiento estriba en que son los miembros del Directorio de Fonafe los que propondrán a las personas que consideren más aptas para formar parte de los directorios de las empresas adscritas a sus respectivos sectores, correspondiendo en todos los casos al Ministro de Economía y Finanzas proponer por lo menos una persona en cada directorio, lo cual no constituye un concurso público, que — como hemos señalado— sería el mecanismo

\footnotetext{
36 Numeral 15.1 del artículo 15 del Reglamento.

37 Anexo I: Procedimiento para la evaluación de las personas propuestas como miembros de los directorios de las empresas en las que fonafe participa como accionista.
} 
ideal para la designación de los directores de las empresas públicas. Ello dada la necesidad de generar autonomía de los directorios respecto de las decisiones políticas que se toman al interior de los sectores que se han identificado como una importante deficiencia en los países de América Latina ${ }^{38}$.

El Decreto Legislativo N.o 1031 prescribe además que la designación de los miembros del Directorio de las empresas del Estado se realizará mediante Acuerdo del Directorio de Fonafe; establece, además, que las designaciones deberán ser publicadas en el Diario oficial El Peruano e instrumentadas en Junta General de Accionistas, de resultar aplicable, lo cual opera conforme a las instrucciones que imparta Fonafe.

En el caso de las empresas del Estado con accionariado privado, la norma preceptúa que deberá garantizarse el ejercicio de los derechos de los accionistas minoritarios, de acuerdo a lo establecido en la Ley General de Sociedades y en el Código Marco del Buen Gobierno Corporativo de las Empresas del Estado. Dicho accionariado privado, como vamos a señalar más adelante, deberá incrementarse de manera paulatina para generar inversión y un mejor control del funcionamiento de la empresa.

Finalmente, en el caso de las empresas con accionariado estatal minoritario, la norma establece que la designación de los directores se realizará conforme a lo establecido en la Ley General de Sociedades. A tales efectos, los representantes, según instrucciones de Fonafe, propondrán en Junta General de Accionistas a los Directores a ser designados. En este caso,

38 Sobre el particular, véase BANCO MUNDIAL. Corporate Governance of State-Owned Enterprises in Latin America. Current trends and country cases. Washington D.C: World Bank, 2014. dicha designación debería efectuarse también por concurso público.

\subsection{Estados financieros de las empresas del Estado}

La norma prescribe que el Fonafe está facultado para suscribir con las empresas bajo su ámbito acuerdos o convenios que establezcan metas empresariales, a través de ratios de gestión y otras herramientas que se desarrollarán en el Reglamento. Estos acuerdos o convenios requieren ser aprobados por acuerdo de directorio de Fonafe. Este precepto tiende, evidentemente, a generar eficiencia en la gestión de las empresas, y debería ser obligatorio, en vez de facultativo.

Por otro lado, la norma establece que la designación de los jefes de los órganos de control institucional, encargados del control de la gestión administrativa, económica y financiera de los recursos y bienes de las empresas del Estado, se efectúa de conformidad con las normas del Sistema Nacional de Control. Es obvio que dichos jefes realizan sus funciones conforme a lo señalado por las normas pertinentes en materia de control gubernamental, sin que exista razón alguna para una regulación distinta.

Los estados financieros de las empresas del Estado son auditados anualmente por auditores externos independientes, designados por la Junta General de Accionistas, conforme lo dispone la Ley General de Sociedades, en base a concurso. Dado lo seńalado en el párrafo anterior, esto no obsta para la realización de las auditorías que correspondan al Sistema $\mathrm{Na}-$ cional de Control, a pesar de lo señalado en su momento por la Contraloría General de la República sobre el particular ${ }^{39}$.

39 Diario La República, 9 de julio de 2008. 


\section{5 ¿Se abre las puertas a la privatización de empresas públicas en la norma?}

El artículo $12^{\circ}$ de la norma materia de comentario establece que por acuerdo del Directorio de Fonafe se determinará que las empresas del Estado deben inscribir un mínimo de $20 \%$ de su capital social en el Registro Público del Mercado de Valores, sujetándose a las disposiciones emitidas por la Comisión Nacional Supervisora de Empresas y Valores (Conasev).

La finalidad de este importante precepto es otorgarle eficiencia a las empresas estatales, permitiendo que sea el mercado el que establezca los parámetros de aquella. Este mecanismo es más eficiente que el control administrativo sobre las empresas públicas en aplicación de la Ley General de Sociedades y permite, además, la participación de la actividad privada en las empresas estatales, dotándolas de capital fresco necesario para la inversión.

A su vez, la tercera disposición complementaria del decreto legislativo mencionado preceptúa que las empresas del Estado podrán recibir nuevos aportes de capital de inversionistas privados, que se sujetarán a las disposiciones y garantías de la Ley General de Sociedades y demás normas aplicables a las empresas privadas. La norma instituye que en el Reglamento se establecerá las disposiciones que permitan fomentar la participación de capitales privados.

La norma establece asimismo que los recursos provenientes de dichos aumentos de capital constituyen recursos propios de las empresas del Estado y serán destinados para el financiamiento de sus actividades. En el marco de los supuestos de esta disposición, las empresas del Estado quedan facultadas a constituir subsidiarias, previo acuerdo de su Junta General de Accionistas y acuerdo aprobatorio del Directorio de Fonafe.
Sobre el particular hay que señalar que, en primer lugar, esto no es algo indebido, desde el punto de vista jurídico y tampoco desde el punto de vista económico. Desde el punto de vista jurídico, nada obsta para que el Estado pueda invertir conjuntamente con los particulares. La norma constitucional habilita la inversión conjunta del Estado y los particulares, especialmente en el contexto de una economía social de mercado y de la aplicación constitucional del principio de subsidiaridad.

Pero, además, desde el punto de vista económico, es un mecanismo eficiente. De hecho, permite que la empresa sea fiscalizada por el mercado y por los propios accionistas, a la vez que genera mayor eficiencia, permite una paulatina administración de esta por particulares ${ }^{40}$, por ende habrá transparencia en el manejo de las cifras, impidiendo que las números sean corregidos por los directivos de las empresas públicas, práctica muy común ${ }^{41}$.

Se ha utilizado para justificar dicho mecanismo el ejemplo de Petrobrás, empresa petrolera brasileńa, que en su momento había adquirido una gran eficiencia y un valor de mercado muy alto a partir de la administración conjunta entre el Estado y el privado. Sin embargo, si bien esto podía constituir una interesante muestra de lo que puede pasar cuando una empresa estatal se comparte con los particulares, la misma no deja de ser tal, con las múltiples distorsiones que hemos seńalado líneas arriba y que las empresas públicas generan. Es decir, si Petrobrás obtenía los resultados antes señalados con la participación de la actividad privada, dicha situación se incrementaría sustancialmente si la empresa fuese dirigida por la actividad privada

40 Sobre el particular, véase Instituto Peruano de Economía. Comentario Diario. Lima: IPE, 26 de junio de 2008. 41 ARIÑO, G. Op. cit., p. 423. 
de manera integral o por lo menos mayoritaria; generando un obvio beneficio para el Estado brasileño en impuestos y regalías, a ello se debe agregar el control más eficiente que permite la participación de los actores privados.

Asimismo, en los últimos tiempos hemos sido testigos de diversos escándalos de corrupción, ampliamente documentados, en la referida empresa estatal brasileña. En consecuencia, como ya lo habíamos adelantado, es más eficiente que la empresa sea dirigida por la actividad privada de manera integral o por lo menos mayoritaria con el fin de obtener más beneficios, expresados estos en impuestos y regalías, reduciendo así la incidencia de actos de corrupción.

A lo mencionado, se debe agregar el hecho de que una de las razones por las cuales el mercado no puede regular de manera adecuada el precio de los hidrocarburos en el ámbito mundial se enfoca en la existencia de carteles formados por empresas estatales. Si las empresas fuesen privadas, los precios se determinarían a través de la oferta y la demanda y no como resultado de los intereses políticos.

\section{EL MECANISMO DE CONTROL DEL PRINCIPIO DE SUBSIDIARIDAD}

Tenemos un importante mecanismo de control, desde la emisión del Decreto Legislativo 1044, Ley de Represión de la Competencia Desleal, el cual define como acto de competencia desleal, en la modalidad de violación de normas, la actividad empresarial desarrollada por una entidad pública o empresa estatal con infracción al artículo $60^{\circ}$ de la Constitución, el cual hemos descrito líneas arriba ${ }^{42}$. Esta es una novedad,

42 Decreto Legislativo N. ${ }^{o}$ 1044, artículo 14. puesto que la norma precedente no consignaba precepto alguno sobre el particular.

Como resultado, este precepto permite al Indecopi o a Osiptel, en su caso, controlar la actividad empresarial del Estado, impidiendo que se vulnere la libre y leal competencia. En primer lugar, resultaba indispensable la existencia de un real mecanismo de control, más allá de los informes que dicha entidad emitía, que carecían de efecto jurídico real. En segundo lugar, dicho control no podría ser asignado al Fonafe — que sería juez y parte en este contexto- ni tampoco al sector al que pertenece la empresa estatal en cuestión.

Una cuestión a dilucidar se encuentra relacionada con la competencia de la autoridad administrativa respectiva para cuestionar la ley que faculta el ejercicio de la actividad empresarial. Es claro que no debiera existir impedimento para ello, dadas las atribuciones otorgadas a favor de la administración pública por el Tribunal Constitucional para aplicar el control difuso de constitucionalidad de las leyes, que, sin embargo,es muy discutible.

Se ha señalado además que la aplicación del principio de subsidiaridad debería ser progresivo, conforme lo dispuesto por la Décima Primera Disposición Final y Transitoria de la Constitución ${ }^{43}$. Sin embargo, esto es discutible, puesto que en realidad la privatización de las empresas públicas tiene por finalidad, entre otras consideraciones, generar competencia y reducir el gasto público.

Finalmente, es evidente que en este caso no se requiere acreditar la adquisición de una ventaja significativa por quien desarrolla dicha

43 «Undécima. Aplicación progresiva de Disposiciones de la Constitución. Las disposiciones de la Constitución que exijan nuevos o mayores gastos públicos se aplican progresivamente». 
actividad empresarial, requisito exigido para encontrarnos ante un acto de competencia desleal en la modalidad de violación de normas, puesto que se asume que toda actividad empresarial del Estado que viole el principio de subsidiaridad genera por sí misma una ventaja indebida a favor de dicha empresa en el mercado.

\subsection{El precedente del Tribunal de Indecopi sobre la materia}

Finalmente, para comprender el principio de subsidiaridad es necesario analizar el precedente recaído en la Resolución N.o 3134-2010/ SC1-INDECOPI, la cual define cómo se interpreta lo dispuesto en el artículo 14 del Decreto Legislativo 1044, en tanto control de la actividad empresarial del Estado; considerándola un caso de competencia desleal en tanto actos de violación de normas, situación en la cual evidentemente dichas empresas gozan de una ventaja indebida en el mercado, como ya lo hemos señalado.

De hecho, en el precedente que es materia de estudio, la Sala de Defensa de la Competencia (en adelante la Sala) señala que el principio de subsidiariedad estatal establece el grado de intervención del Estado en la vida económica del país, constituyendo un límite al campo de acción estatal respecto de la libertad de los ciudadanos para hacer empresa. Con ello, el precedente deja en claro que nos encontramos ante un mecanismo de intervención en la economía que debe estar sometido a evidentes parámetros a fin de que no perjudique al mercado ${ }^{44}$.

44 Para una posición crítica del precedente, cfr. OCHOA, C. «El principio de subsidiariedad de la iniciativa pública. Análisis del precedente aprobado por la Resolución N. ${ }^{\circ}$ 3134-2010/SC1-INDECOPI». En: Actualidad Jurídica, tomo 206. Lima: Gaceta Jurídica, 2011, p. 33 y ss.
Asimismo, el precedente establece que la limitación establecida en la Constitución se aplica a toda actuación estatal que consista en la producción, distribución, desarrollo o intercambio de productos o servicios de cualquier índole, con independencia de la existencia o no de ánimo lucrativo y de la forma jurídica que adopte el Estado para prestar el bien o servicio. Con ello, conforme al precedente, el principio de subsidiaridad no es aplicable únicamente a empresas estatales, como sí ocurrió en el caso que generó el precedente que estamos estudiando, donde es una universidad y no una empresa la que vulnera el principio antes señalado.

Además, el precedente establece que no constituye actividad empresarial y se excluye de la limitación constitucional el ejercicio de potestades de ius imperium y la prestación de servicios asistenciales. En el primer caso nos encontramos ante una relación propiamente de derecho público, que no es la naturaleza de la relación entre consumidor y proveedor. En el segundo caso, no es aplicable el principio de subsidiaridad, puesto que no existe competencia alguna con la actividad privada, y se constituyen en actividades destinadas a corregir desigualdades.

En cuanto a los parámetros de la actividad empresarial del Estado, el precedente materia de análisis establece que, para ser lícita, la actividad empresarial estatal debe, en primer lugar, contar con una ley expresa aprobada por el Congreso de la República que autorice su desarrollo. Asimismo, el precedente señala que la ley debe establecer de manera clara y patente que la empresa o entidad estatal se encuentra habilitada para producir, distribuir, desarrollar o intercambiar bienes y servicios en determinada actividad, no admitiéndose autorizaciones tácitas ni interpretaciones analógicas o extensivas de la habilitación. Este criterio de la Sala es 
de particular importancia para determinar que efectivamente la universidad se encontraba violando el principio de subsidiaridad, como veremos más adelante.

El precedente señala, en efecto, que la actividad empresarial del Estado debe cumplir un objetivo de alto interés público o de manifiesta conveniencia nacional. Sin embargo, establece que la autoridad de competencia no puede discutir si la actividad empresarial satisface un objetivo de tal naturaleza. En tal sentido, se limitará a comprobar que la ley que autoriza la actividad señala la razón de interés público o conveniencia nacional que sustentó su aprobación. Solo si la ley no precisa la justificación,se incumplirá este requisito.

El precedente para explicar por qué Indecopi no se puede pronunciar respecto a este requisito, señala que esto ocurre debido a que es el Congreso que debe determinar si se verifica dicho parámetro, lo cual nos parece discutible. De hecho, la ausencia de este requisito implica una vulneración al principio que venimos analizando, razón suficiente para considerar que nos encontramos ante una empresa estatal que está generando competencia desleal. En consecuencia, este requisito debería ser analizado también por la Comisión, que debe señalar que la empresa o entidad se encuentra violando el principio de subsidiaridad ${ }^{45}$.

\subsection{El precedente de la Sala en cuanto a la existencia de oferta privada suficiente}

En primer lugar, debe tenerse en cuenta el concepto de mercado relevante. Para ello, la reso-

45 Para una visión distinta, leer AGURTO, C. y ALVARADO, O. "No todo tiempo pasado fue mejor. Algunos alcances sobre el principio de subsidiariedad y la Resolución N. $3134-2010 / S C 1-I N D E C O P I ”$, en Actualidad Jurídica, tomo 206, Lima: Gaceta Jurídica, 2011, p. 61. lución señala que debe recurrirse a lo dispuesto por el artículo 6 del Decreto Legislativo N. ${ }^{\circ}$ 1034, que lo define como aquel compuesto a su vez por dos elementos. Primero, el mercado de producto relevante que es, por lo general, el bien o servicio materia de la conducta investigada y sus sustitutos. Asimismo, el mercado geográfico relevante es el conjunto de zonas geográficas donde están ubicadas las fuentes alternativas de aprovisionamiento del producto relevante.

Ahora bien, señala el precedente que un primer supuesto es aquel en el cual concurren con la empresa o entidad estatal dos o más empresas privadas no vinculadas ${ }^{46}$. En este escenario se presume que las condiciones de competencia son las adecuadas y la oferta privada es suficiente. Por ello, la entidad o empresa estatal denunciada tiene la carga de probar, de un lado, que los privados establecidos no pueden absorber la demanda que liberaría en caso se retire y, de otro lado, que existen altas barreras a la entrada que impiden el ingreso de nuevos proveedores con capacidad de satisfacer la demanda que se liberaría.

Debe entenderse que ambos requisitos son concurrentes, puesto que el hecho de que los proveedores existentes no puedan absorber la demanda se resolvería a través del ingreso de nuevos competidores una vez que la intervención en dicho mercado se hubiera reducido. Señala la resolución que el primero de dichos requisitos requiere un análisis que pasa por determinar la capacidad instalada de las empresas, lo cual no es fácil de verificar. Asimismo, el segundo requisito implica un conjunto de supuestos que incluyen, evidentemente, las

46 Véase BULEJE, C. "La actividad empresarial estatal (lo que no se ve)", en Themis, n. ${ }^{\circ}$ 61, Lima: Pontificia Universidad Católica del Perú, 2012, p. 178 y ss. 
barreras burocráticas a las que nos referiremos más adelante.

Si es que no se cumplen ambos requisitos, es evidente que la entidad o empresa se encuentra violando el principio de subsidiaridad. En este caso, además, la resolución nos recuerda que este criterio se encuentra establecido legalmente en el artículo 3 del Decreto Supremo N. ${ }^{\circ}$ 034-2001-PCM, en el cual también se asigna la carga de la prueba, cual corresponde a la entidad denunciada.

En el segundo supuesto en que en el mercado relevante participen una empresa privada y una empresa estatal, no opera la presunción de oferta privada suficiente, por lo que, para concluir que la intervención estatal no es subsidiaria, la autoridad — a partir de sus actuaciones de instrucción y las pruebas aportadas por el denunciante- deberá constatar que la empresa privada cuenta con las condiciones para satisfacer la demanda que eventualmente se libere o que, en caso la oferta establecida no sea suficiente, no existen barreras que limiten la entrada de competidores potenciales.

Si dichas barreras no existen, siempre será posible que a ese mercado ingresen nuevos competidores, a fin de satisfacer la demanda liberada. Asimismo, es claro que la carga de la prueba en este caso corresponde a la autoridad, en aplicación del Decreto Legislativo N. ${ }^{\circ} 1044$, la cual se encontraría en mejor capacidad para probar. Los mecanismos para evaluar ello son equivalentes a los empleados en el supuesto anterior.

El tercer supuesto es que en dicho mercado solo participe la empresa o entidad estatal. Aquí no existe oferta privada, por lo que se evaluará la presencia de barreras a la entrada. Si no existen barreras, el precedente señala que lo más pro- bable es que el sector privado no se encuentre interesado en incursionar en dicho mercado, concluyéndose - a diferencia de lo que ocurre en los dos primeros escenarios- que la empresa estatal cumple un rol subsidiario.

Continúa la Sala señalando que, en caso de que se determine que existen barreras a la entrada significativas, la participación también será subsidiaria, salvo que se defina que la presencia de la empresa o entidad estatal debe cesar al ser la barrera que desincentiva la entrada de los privados. Es preciso señalar que esto ocurre en muchos casos, puesto que la inversión privada se retrae cuando se encuentra al interior de un mercado muy regulado, como aquel donde participa una empresa estatal, que posee mecanismos para disuadir la participación de los privados.

\subsection{Barreras burocráticas}

De una lectura superficial del precedente se podría llegar a la conclusión de que la empresa estatal materia de análisis satisface el principio de subsidiaridad cuando existen barreras de entrada que impiden a la actividad privada satisfacer la demanda de los consumidores. Ello en realidad es cierto, pero solo a medias. De hecho, podría ocurrir que la responsabilidad de dichas barreras le corresponda al propio Estado, por lo tanto, se estaría ante una barrera burocrática.

En este orden de ideas, el precedente materia de análisis señala entonces que, si al realizar el análisis de subsidiariedad se detecta que las barreras a la entrada se encuentran contenidas en instrumentos normativos que la Comisión de Eliminación de Barreras Burocráticas se encuentra facultada a remover, la autoridad deberá remitir los actuados a la referida comisión para que esta analice la pertinencia de iniciar 
un procedimiento de oficio por imposición de presuntas barreras burocráticas ilegales o carentes de razonabilidad.

Finalmente, señala el precedente, si la barrera que impide el acceso al mercado se encuentra contemplada en una disposición que la Comisión de Eliminación de Barreras Burocráticas no se encuentra facultada a analizar, la función que debe asumir la autoridad consiste en ejercer la "abogacía de la competencia" o "promoción de la competencia", que le permite emitir opinión, exhortar o recomendar a las autoridades legislativas, políticas o administrativas sobre la implementación de medidas que aseguren la leal competencia, conforme al artículo 25 literal g) del Decreto Legislativo N.o 1044.

\section{El sentido de la resolución de la Sala}

Es evidente que el Indecopi se ha pronunciado en el precedente que venimos señalando en aplicación de esta norma y de sus alcances. Básicamente, el análisis de la Sala se ha centrado en definir si la universidad denunciada cumple con el requisito de autorización a través de ley expresa para efectos de la realización de la actividad empresarial, que se encuentra debidamente probada. En este sentido, es evidente que dicha actividad debe tener directa relación con los fines de la universidad, formar profesionalmente a los estudiantes, lo cual claramente no es el caso.

De hecho, la Sala ha señalado que la venta de pollos a la brasa realizada por "Pollería y Parrillería Universitaria" del CIS Frigorífico no se ajusta a la habilitación expresa contemplada en la Ley N.o 23733, ley universitaria, incumpliendo con ello el requisito previsto en el artículo 60 de la Constitución, por lo tanto, se confirma la resolución que declaraba fundada la denuncia contra la Universidad Nacional del Altiplano.

\section{BIBLIOGRAFÍA}

AGURTO, C. y ALVARADO, O. "No todo tiempo pasado fue mejor. Algunos alcances sobre el principio de subsidiariedad y la Resolución N.o 3134-2010/SC1-INDECOPI", en Actualidad Jurídica, tomo 206, Lima: Gaceta Jurídica, 2011.

ARIÑO, G. Principios de derecho público económico. Granada: Comares, 1999, pp. 440-441.

ARIÑO, G., DE LA CUÉTARA, J. y MARTÍNEZ, J. L. El nuevo servicio público. Madrid: Marcial Pons, 1997.

BANCO MUNDIAL. Corporate Governance of State-Owned Enterprises in Latin America. Current trends and country cases. Washington D.C.: World Bank, 2014.

BERNANKE, B. y FRANK, R. Principios de economía. Madrid: McGraw-Hill, 2007.

BULEJE, C. La actividad empresarial estatal (lo que no se ve), en Themis n. ${ }^{\circ}$ 61. Lima: Pontificia Universidad Católica del Perú, 2012, pp. 167-186. Disponible en http://revistas.pucp.edu.pe/index. php/themis/article/view/9038

CESPEDES, A. Conjeturas sobre algunos aspectos generales el funcionamiento y la regulación de las empresas públicas peruanas, en Revista de Derecho Administrativo n. ${ }^{\circ}$ 5, Lima: Pontificia Universidad Católica del Perú, 2008, pp. 270-281. Disponible en https://bit.ly/3bqcmgm

Decreto Legislativo N.o 1031 (23 de junio de 2008). Decreto Legislativo que promueve la eficiencia de la actividad empresarial del Estado. Presidencia de la República. Disponible en https://bit.ly/2Rl8mXB

Decreto Legislativo N. ${ }^{\circ}$ 1044. Decreto Legislativo que aprueba la Ley de Represión de la Competencia Desleal (25 de junio de 2008). Presidencia de la República. Disponible en https://bit.ly/3uNDZHS

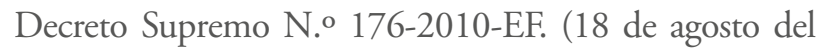
2010). Aprobación del Reglamento del Decreto Legislativo No 1031, que promueve la eficiencia de la actividad empresarial del Estado. Presidencia de la República.

DE VAL PARDO, I. Administración de entidades públicas. Madrid: Instituto de Estudios Económicos, 1999.

DROMI, R. Derecho administrativo. Buenos Aires: Ciudad Argentina, 2000.

DUVERGER, Maurice. Instituciones politicas y derecho constitucional. Barcelona: Ariel, 1962.

GUZMAN, C. Procedimiento Administrativo General. Lima: Instituto Pacífico, 2020. 
GUZMAN, C. La constitución politica: Un análisis funcional. Lima: Gaceta Jurídica, 2015, 870 pp.

GUZMAN, C. "Las teorías existentes sobre el servicio público", en Foro Jurídico n. ${ }^{\circ}$ 1. Lima: Pontificia Universidad Católica del Perú, 2002.

INSTITUTO PERUANO DE ECONOMÍA. Comentario Diario. Lima: IPE, 26 de junio de 2008.

HAURIOU, A. Derecho constitucional e instituciones politicas. Barcelona: Ariel, 1980.

HUAPAYA, M. y TERRAZOS, J. Principio de subsidiariedad: consideraciones respecto a la aplicación constitucional del numeral 14.3 del D. Leg. N. ${ }^{\circ}$ 1044 en materia de actividad empresarial del Estado. Derecho \& Sociedad, n. ${ }^{\circ}$ 31, Lima, 2008.

KAFKA, F. Teoría económica. Lima: Universidad del Pacífico, 1994.

KRESALJA, B. «La reserva de actividades económicas a favor del Estado y el régimen de los monopolios en las Constituciones de 1979 y 1993", en Ius et Veritas 11, n. ${ }^{\circ} 22$. Lima: Pontificia Universidad
Católica del Perú, 2001, pp. 272-306. Disponible en https://bit.ly/3ybiqmO

KRESALJA, B. "El rol del Estado y la gestión de los servicios públicos", en Themis n. ${ }^{\circ}$ 39. Lima: Pontificia Universidad Católica del Perú, 1999.

OCHOA, C. Bases fundamentales de la Constitución económica de 1993. La Constitución de 1993, análisis y comentarios. Lima: CAJ, 1995.

OCHOA, C. El principio de subsidiariedad de la iniciativa pública. Análisis del precedente aprobado por la Resolución N.o 3134-2010/SC1-INDECOPI. Actualidad Jurídica, tomo 206. Lima: Gaceta Jurídica, 2011.

PAREDES, C. La tragedia de las empresas sin dueño: el caso Petroperú. Huancayo: Fondo Editorial de la Universidad Continental, 2020, 284 pp.

Tribunal Constitucional. STC N. ${ }^{\circ} 01535-2006-A A / T C$ del 31 de enero de 2008.

VICKERS, J. y YARROW, G. Un análisis económico de la privatización. México: Fondo de Cultura Económica, 1991. 